\title{
TERRITORIALIDADES DA PESCA NO MÉDIO RIO AMAZONAS
}

\author{
Territorialities of the fishery in the medium Amazonas river
}

Dilson Gomes Nascimento

Secretaria de Estado da Educação e Qualidade do Ensino - SEDUC/AM

dgdilson1@gmail.com

Manuel de Jesus Masulo da Cruz

Universidade Federal do Amazonas - UFAM

masulo@bol.com.br

RESUMO: Discutir sobre as transformações na pesca extrativa no ambiente de rio, no médio rio Amazonas, constitui o objetivo central deste artigo. A pesca representa mais que uma fonte de renda aos ribeirinhos, é fonte de alimentos e de inúmeras relações territoriais estabelecidas nos espaços historicamente ocupados pelos camponeses. Com base na observação e na entrevista dos ribeirinhos do município de Parintins-AM, expomos algumas das transformações ocorridas na pesca no rio Amazonas, sobretudo no que concerne à captura e comercialização dos peixes de couro/lisos. As transformações observadas representam tanto novas relações ambientais, quanto novas técnicas na pesca o que conferiu, a esta atividade, novos contornos.

Palavras-chave: Pesca; Territorialidade; Rio Amazonas.

ABSTRACT: The main objective of this article is to discuss the transformations in extractive fishery in the river environment, specifically in the medium Amazonas River. The fishery represents more than a source of income for the riverine, it is a source of food and numerous territorial relations established in the spaces historically occupied by peasants. Based on the observation and the interview of the riverine of the municipality of Parintins-AM, we show some of the changes that occurred in the fishery of the Amazonas River, especially in what concerns the capture and commercialization of leather/smooth fish. The observed transformations represent new environmental relations, as well as new fishery techniques, which gave this activity, new contours.

Keywords: Fishery; Territoriality; Amazonas river.

\section{INTRODUÇÃO}

Entender as transformações ocorridas na relação dos ribeirinhos com seu ambiente de vida/trabalho, especificamente com o rio, é o ponto central deste trabalho. Desde meados do século XIX, quando muitas famílias camponesas já habitavam as várzeas no médio rio Amazonas, a pesca extrativa nos ambientes de rio e de lago sempre fizera parte da vida ribeirinha.

O presente artigo expõe parte dos resultados da pesquisa realizada entre os ribeirinhos do município de Parintins-AM, com o objetivo de compreender as 
transformações ocorridas, sobretudo, na relação desses sujeitos com seus espaços de vida e trabalho: a terra e a água.

A coleta dos dados foi realizada entre 2014-2016, tendo sido realizadas entrevistas e o acompanhamento em campo dos ribeirinhos, sobretudo, os mais experientes, em atividades como o preparo/limpeza dos lanços de pesca, pescarias, comercialização do pescado, entre outros.

A pesca no ambiente de rio até as décadas de 1970/80 encontrava-se mais restrita às espécies de couro/liso como a piramutaba (Brachyplatystoma vaillantii), o filhote/piraíba (Brachyplatystoma filamentosum), a dourada (Brachyplatystoma flavicans) e o mapará (Hypophthalmus marginatus), cuja comercialização era em postas secas após a salga. Já no ambiente de lago, as espécies mais procuradas eram o pirarucu (Arapaima gigas) e o jacaré. Até este período a Amazônia estava voltada para a economia extrativa vegetal, do qual a borracha foi um de seus maiores expoentes, sobretudo nos altos rios amazônicos. Em Parintins, o cacau foi um dos maiores produtos vegetais extrativo-cultivados para exportação.

Com o declínio da economia extrativa, com a redução dos interesses tanto do capital, quanto do próprio estado pelo setor um novo momento de destaque para o médio rio Amazonas foi a agricultura da juta (Corchorus capsularis). O berço desta fibra vegetal na Amazônia ocorreu no município de Parintins-AM, por volta da década de 1930, quando foi aclimatada por imigrantes japoneses. Seu período de maior destaque econômico foi entre as décadas de 1960 e 1970.

O sucesso da juta, entretanto foi breve e logo se deu seu declínio, por volta de 1980 já não era mais lucrativa para as empresas processadoras e exportadoras, dado o seu substituto sintético introduzido no mercado, o qual era utilizado no lugar da fibra natural.

A partir de então as famílias camponesas que viviam nas margens dos rios amazônicos passaram a se dedicar à agriculta de ciclo curto, à pesca (de rio e de lago), e à pequena criação (pecuária bovina) como uma forma de adequação ao novo momento, tendo seus produtos destinados para o abastecimento da cidade de Parintins principalmente.

Entretanto, defendemos a ideia de que a tríade pesca-agricultura-pecuária sempre foram presentes entre as famílias ribeirinhas no médio rio Amazonas. Mesmo durante a economia extrativa, estas famílias camponesas tinham uma pequena criação de gado, principalmente na várzea; mantinham a agricultura para consumo próprio das famílias, dos amimais ou para trocas; além de manterem a pesca como fonte de alimento ou de renda e, neste ponto, também se pode inserir a caça de animais silvestres.

Dito isto, afirmamos que em nenhum momento os ribeirinhos no médio rio Amazonas especializaram-se em extratores/coletores, pescadores ou mesmo agricultores. Porém, as famílias por questões de renda, podem dedicar-se em maior ou menor grau a certas atividades, das quais possa ter maior retorno financeiro ou um retorno mais rápido quando comparadas as atividades entre si. 
Há famílias que julgam a pesca como mais vantajosa quando comparada à agricultura, por exemplo, pois permite o retorno mais rápido que a agricultura de ciclo curto na várzea. Por isso, entendemos as famílias ribeirinhas praticantes de uma diversidade de atividades, as quais são fundamentais para a permanência camponesa no campo.

Este artigo apresenta algumas transformações ocorridas na pesca no médio rio Amazonas, particularmente no ambiente de rio. Para situar o leitor, é preciso pontuar que a pesca realizada no rio Amazonas era com o uso de apetrechos (arreios) como o arpão e a flecha, já que as redes de pesca só foram inseridas quando da popularização dos fios sintéticos por volta da década de 1970.

Com a introdução das redes de pesca para a captura de peixes no rio, principalmente os siluriformes (ou peixes de fundo) como o surubim (Pseudoplatystoma fasciatum), os espaços de pesca passaram a ser construídos e usados de forma comum. A criação das territorialidades da pesca no rio advém da construção dos chamados lanços de pesca, os quais são descritos ao longo do trabalho.

\section{MATERIAIS E MÉTODOS}

A pesquisa foi de cunho exploratório, por meio de um estudo de caso envolvendo as comunidades rurais São Sebastião do Boto e Santa Rita do Boto, no município de Parintins-AM, extremo leste do estado do Amazonas.

O estudo foi realizado entre os anos de 2014-2016, tendo como objetivo principal compreender as transformações sócio-espaciais (SOUZA, 2013) ocorridas no campo, no médio rio Amazonas.

Foi utilizada a observação participante, por meio da qual foi possível acompanhar/vivenciar diversas atividades desenvolvidas pelos ribeirinhos ao longo do ano, entre 2014 e 2015. Acompanhamos os ribeirinhos em atividades rotineiras como no trato com os animais de criação, nas atividades agrícolas, nas pescarias, entre outras.

Os trabalhos de campo entre os ribeirinhos permitiram o contato direto com os sujeitos da pesquisa e o acompanhamento de suas atividades como pesca, agricultura, pecuária, festas dos santos padroeiros entre outros.

No tocante à pesca extrativa, para o conhecimento acerca das transformações ocorridas, foram realizadas entrevistas semiestruturadas em dois momentos: primeiro, com os moradores mais antigos das comunidades e, posteriormente, com os maiores de dezoito anos de idade.

Entre os moradores mais antigos, com idades entre 60 e 80 anos, foi possível compreender os aspectos históricos que envolveram as transformações tanto na pesca, quanto em outros aspectos da vida ribeirinha. A escolha por esse grupo etário, na fase inicial do trabalho de campo, ajudou-nos no levantamento das características das comunidades pesquisadas por volta de meados do século 20 . 
Muitos desses informantes, como eles próprios relataram, nasceram nas referidas comunidades, ou moram nestes locais desde jovens, quando constituíram família.

Já entre os moradores mais jovens, seus relatos forneceram subsídios para o nosso entendimento quanto às características atuais do campo, no médio rio Amazonas. $O$ contato com estes sujeitos foi estabelecido na segunda etapa da pesquisa, quando buscou-se compreender como se estabelecem as "novas" relações dos ribeirinhos com seus ambientes de vida e de trabalho.

\section{RESULTADOS E DISCUSSÕES}

\section{Os ribeirinhos e as relações socioambientais}

As territorialidades camponesas estabelecidas atualmente na área pesquisada, revelam não somente as transformações mais gerais relacionadas à economia, mas sobretudo à redução dos recursos ictiofaunísticos em contexto local.

Para Raffestin (1993):

[...] a vida é tecida por relações, e daí a territorialidade poder ser definida como um conjunto de relações que se originam num sistema tridimensional sociedade-espaço-tempo em vias de atingir a maior autonomia possível, compatível com os recursos do sistema... (p. 160-161).

Das relações dos homens com a natureza, o meio físico, motivadas por suas necessidades naturais decorrem as estratégias para assegurar os meios de vida dos grupos, como destacado por Candido (2010), de tal modo que, mesmo sendo motivadas por necessidades naturais, "impulso orgânicos", estas são atendidas por meio de iniciativas humanas,

[...] que vão se complicando cada vez mais, e dependem do grupo para se configurar. Daí as próprias necessidades se complicarem e perderem em parte seu caráter estritamente natural, para se tornarem produtos da sociedade. De tal modo a podermos dizer que as sociedades se caracterizam, antes de tudo, pela natureza das necessidades de seus grupos, e os recursos de que dispõem para satisfazê-las (CANDIDO, 2010, p. 28).

As territorialidades da pesca, mais que uma necessidade de assegurar um recurso natural, constituem-se numa necessidade social dos grupos de camponesesribeirinhos, das turmas de pescadores, já que a territorialidade só se efetiva mediante as relações entre os sujeitos.

As territorialidades da pesca na área pesquisada têm se manifestado tanto individual, quanto socialmente em defesa dos territórios camponeses, inclusive com ações intercomunitárias por meio das discussões do Acordo de Pesca na APA 
Nhamundá, relacionadas às territorialidades da pesca no ambiente de lago, como destacado por Pires (2015).

De acordo com McGrath e Gama (2005) a partir da década de 1980, quando a economia da juta entrou em decadência, intensificou-se e expandiu a pesca comercial. Como há conflitos de interesse entre a pesca tradicional e a pesca comercial, os camponeses-ribeirinhos criaram estratégias de defesa dos recursos pesqueiros por meio do controle sobre os locais de pesca.

Não trabalhamos com a ideia de que os ribeirinhos especializaram-se em pescadores, pois na prática, realizam um conjunto de atividades que contribuem para a sua permanência no campo. Dedicam-se em maior ou menor grau à pesca, sobretudo pela vantagem (enquanto atividade econômica) de ter a comercialização garantida de seu produto, o pescado, sem que isto seja o suficiente para uma generalização dos ribeirinhos enquanto pescadores.

Não se deve negligenciar ainda, que o destaque da pesca extrativa sobre as demais atividades econômicas na várzea, também foi favorecido pelas transformações técnicas ocorridas no setor e pelo acesso ao dinheiro, possibilitando ao camponêsribeirinho adquirir (barcos, canoas, motor rabeta, caixas de isopor, gelo, redes de pesca, etc.) e/ou produzir seus próprios meios de produção como os seus apetrechos (arreios), a partir do surgimento dos fios sintéticos, etc. "A maneira pela qual os homens produzem os seus meios de subsistência depende, antes de mais nada, da natureza dos meios de subsistência que encontram prontos e que necessitam reproduzir" (MARX, 1937-1947 apud CANDIDO, 2010, p. 29).

O entendimento das transformações sócio-espaciais na várzea considera as relações sociedade-espaço-tempo como proposto por Raffestin (1993), ou no dizer de Santos (2006) de que "[...] A cada lugar geográfico concreto corresponde, em cada momento, um conjunto de técnicas e de instrumentos de trabalho, resultado de uma combinação específica que também é historicamente determinada" (p. 34-35).

Quando consideradas em conjunto, agricultura-pesca-pecuária têm grande importância para a manutenção econômica das famílias camponesas na várzea, porém, é preciso destacar as peculiaridades que as envolvem e, principalmente, quando se pretende entender como estas, enquanto "meios de vida", contribuem para o "equilíbrio" da vida camponesa (CANDIDO, 2010).

Isto nos permite entender, no caso da pesca, como foram instituídas as regras de uso dos lagos em parte da APA Nhamundá e como ocorreu o estabelecimento de territorialidades nos espaços de acesso livre do rio Amazonas, entre outras questões envolvendo as territorialidades camponesas.

\section{As transformações da pesca no ambiente de rio}

Considerando o ambiente de rio como um espaço de acesso livre é possível afirmar que até a década de 1990 quando a pesca no rio objetivava a captura de "peixes de superfície", qualquer pessoa, a qualquer momento, podia utilizar-se dos espaços do rio para a pesca. A partir da década de 2000 , quando a procura pelos "peixes de fundo" (siluriformes) como o surubim e o caparari (Pseudoplatystoma tigrinum) 
aumentou, os camponeses-ribeirinhos por meio do trabalho coletivo passaram a limpar o leito do rio para a pesca de lanço e reivindicaram para si o uso dessas porções do rio por meio duma territorialidade.

Essas territorialidades da pesca foram criadas diante de um contexto de maior pressão sobre a pesca em função de novas tecnologias, maiores investimentos no setor, maior demanda por pescado nas cidades e, contraditoriamente, da menor disponibilidade do pescado.

\begin{abstract}
Até aproximadamente a década de [19]40, a pesca na Amazônia era realizada por uma frota muito primitiva, formada por embarcações pequenas, exclusivamente de madeira e com propulsão a remo ou vela. Nos anos [19]60, a liberação de incentivos fiscais para a região e a abertura da economia a grandes empresas, que vieram de outras regiões do Brasil, favoreceu o rápido desenvolvimento tecnológico da pesca. As embarcações ganharam motores e artes de pesca mais resistentes (redes de náilon) e mais eficientes na captura de peixes e crustáceos (BATISTA; ISAAC \& VIANA, 2004, p. 70).
\end{abstract}

As transformações regionais em consonância com as políticas desenvolvimentistas do governo brasileiro também colaboraram para as transformações em âmbito local.

\begin{abstract}
Na década de [19]60, três eventos são marcantes para os novos rumos da atividade pesqueira na região. $O$ primeiro foi a introdução e a popularização do polietileno ou isopor como isolante térmico, permitindo a conservação e a acumulação do pescado por mais tempo, viabilizando ampliar o raio de ação da frota. O segundo foi a criação da Zona Franca de Manaus, que causou um rápido crescimento da população urbana da cidade, via imigração de ribeirinhos. Estes tinham como hábito a captura e o consumo diário do pescado (MESCHKAT, 1961; SMITH, 1979), como ainda segue ocorrendo na zona rural (CERDEIRA et al., 1997; BATISTA et al., 1998). Nas cidades, eles causaram um aumento na demanda por pescado, incrementando a pressão consumidora e assim estabelecendo um importante mercado urbano. Adicionalmente, ocorreu imigração para Manaus de pessoas vinculadas ao pólo industrial, atraídas pela perspectiva de emprego na região. Em terceiro lugar, temos a introdução de linhas sintéticas, as quais popularizaram as redes de arrasto e de espera, facilitando o aumento do esforço de pesca e conseqüentemente da produção (BATISTA; ISAAC \& VIANA, 2004, p. 66).
\end{abstract}

No caso estudado por Cruz (2007, p. 214) o lanço de pesca realizado "[...] pelos camponeses-ribeirinhos consiste na preparação da terra no período de águas baixas (vazante/seca) para a prática pesqueira durante o período das águas altas (enchente/cheia) nos lagos e rios [...]". Segundo o referido autor, diante da impossibilidade dos camponeses-ribeirinhos tornarem-se donos de porções da água, é o trabalho camponês-ribeirinho contido no preparo dos lanços para a pesca que permite ao dono da terra apropriar-se de determinada porção da água em frente sua 
propriedade, reclamando para si o direito de uso, no caso dos lanços nos lagos e, para o grupo, no caso dos lanços no rio.

No caso aqui estudado sobre as territorialidades da pesca no ambiente de rio, a lógica de apropriação desses espaços d'água para a pesca equivalem-se às descritas a cima, porém, o processo de limpeza do leito do rio Amazonas, como constatado na pesquisa, foi gradual, não ocorrendo de um ano para o outro como ocorre na limpeza dos lanços de pesca no ambiente de lago (CRUZ, 2007).

O preparo dos lanços de pesca no Médio rio Amazonas ocorreu por meio trabalho coletivo. Os camponeses-ribeirinhos retiravam os troncos de árvores (paus) que ficavam expostos no leito do rio durante a vazante/seca com uso de ferramentas como machado e terçado (facão).

\begin{abstract}
A limpeza do rio começou quando começou a secar esse beiradão [leito menor do rio], a gente topava aqueles paus pela beira e cortava. Nessa área aí de baixo [lanço Santo Agostinho] já era limpa, aqui pra cima [lanço da Boca do Boto] que a gente ainda cortava os paus. Ninguém pescava nesse meio da Boca do Boto pra baixo, tinha muito pau aí... (R. O. S. 49 anos. Camponês-ribeirinho. Pesquisa de campo. Março de 2015).
\end{abstract}

Os troncos submersos, de acordo com os camponeses-ribeirinhos eram retirados com o auxílio de redes de pesca, lançadas sucessivamente para remover os troncos de árvores do leito do rio: "jogavam uma, duas, três malhadeiras até limpar o fundo do rio".

Esse trabalho de preparo dos lanços de pesca no Médio rio Amazonas também foi complementado com a participação de barcos de pesca interessados na comercialização do pescado, os quais utilizando cabos de aço, auxiliavam na retirada dos troncos de árvores do leito do rio, conforme observado por Cruz (2007) no Baixo rio Manacapuru.

Antes do preparo dos lanços de pesca no Médio rio Amazonas, os camponesesribeirinhos pescavam a dourada no ambiente de rio com as mesmas malhadeiras utilizadas para a pesca do tambaqui (Colossoma macropomum) no ambiente de lago. Aos poucos foram criando novas malhadeiras apropriadas para a captura dos grandes bagres no rio.

Vale ressaltar que, localmente, a confecção das malhadeiras próprias para a pesca no rio só foi possível porque os camponeses-ribeirinhos prepararam também o ambiente, o espaço, para esse tipo de pesca, por meio da limpeza coletiva dos lanços de pesca. Caso o leito do rio permanecesse "sujo", a introdução das redes de arrasto seria inviável.

\footnotetext{
Naquele tempo [década de 1970] pescava só de arpão, de linha... Uma noite uns "arigó" que compraram um terreno lá, pegaram uma malhadeirota [malhadeira pequena] de pescar tambaqui e inventou de dá uma bubuiada [lançar a rede à deriva no rio]... Aí, veio enrolada de dourado. Era só bubuiando mesmo, e ainda era só metido boia de aninga. [...] Naquele
} 
tempo não se fazia essa pescaria [de bubuia e rede de arrasto no rio] porque tinha muito peixe. Essa pescaria de bubuia veio dali de baixo [Estado do Pará]. Então eles [os introdutores da bubuia] faziam altas as malhadeiras deles. Agora, de todas as malhadeiras que nós usa aqui é difícil tu ver uma malhadeira alta, com mais de vinte e cinco malhas de altura, trinta malhas é o máximo. Antigamente não, era trinta e cinco malhas de altura a mais baixa... Tinha uns com quarenta malhas. Abordo do barco [de recreio] era só um comentário: "fulano tem uma malhadeira de quarenta malhas!" Mas era um entralho por cima d'água, num [não] botavam chicote, agora que a gente coloca. É vinte e cinco malhas, trinta malhas, mas coloca chicote, conforme a fundura. Só pesca arrastando. [...] Aí bota quatro, cinco braças de chicote, na beira! Conforme a fundura. Esses lugar daqui, por exemplo, no pino da cheia, pode pegar uma malhadeira e colocar cinco braças de chicote e soltar lá. Até essas aí do "meio do rio" é vinte e cinco malhas, só aumenta o comprimento (M. S. N. 63 anos. Camponêsribeirinho. Pesquisa de campo. Dezembro de 2015).

Somente a dourada (Brachyplatystoma rousseauxil) era capturada, outros peixes de fundo como o surubim (Pseudoplatystoma fasciatum) escapavam por baixo das redes, protegidos pelo leito "sujo" do rio (Figura 1) até a década de 1990.

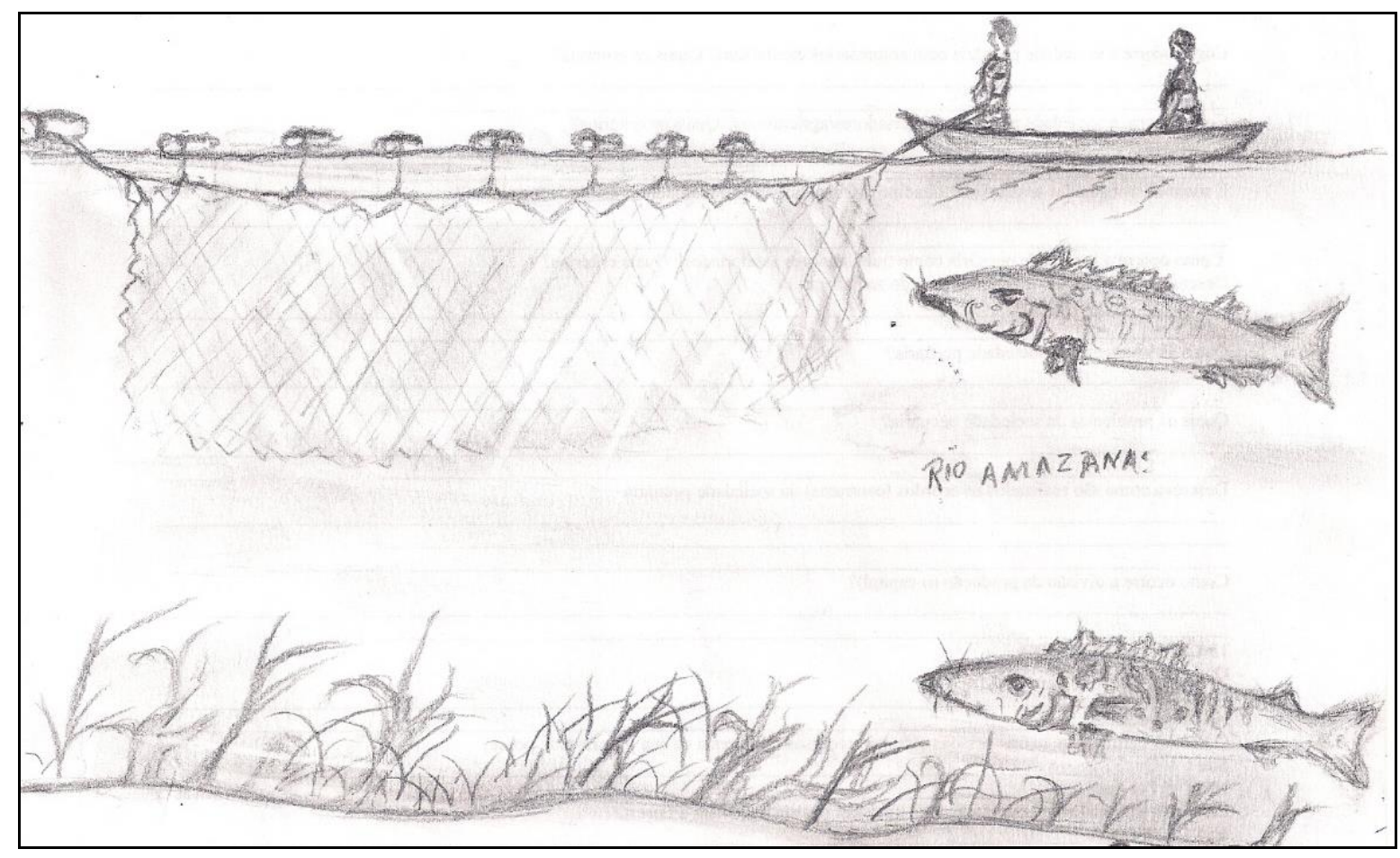

Figura 1: Pesca no Médio rio Amazonas - década de 1990. Desenho: Ronildo de Souza Bentes, 2015. Organizador: Nascimento, 2015. Trabalho de campo, 2014-2015.

A partir da década de 2000 a pesca no ambiente de rio passou a ser realizada pelas turmas de pescadores nos lanços de pesca (Figura 2). Foram realizadas a confecção de redes de emalhar adaptadas para esse tipo de pesca, além da limpeza 
do leito do rio indispensáveis para a construção dos territórios da pesca camponeses. Por sua vez, para o uso e a manutenção dos territórios da pesca foram instituídas regras pelos camponeses-ribeirinhos baseadas no "sistema de espera da vez".

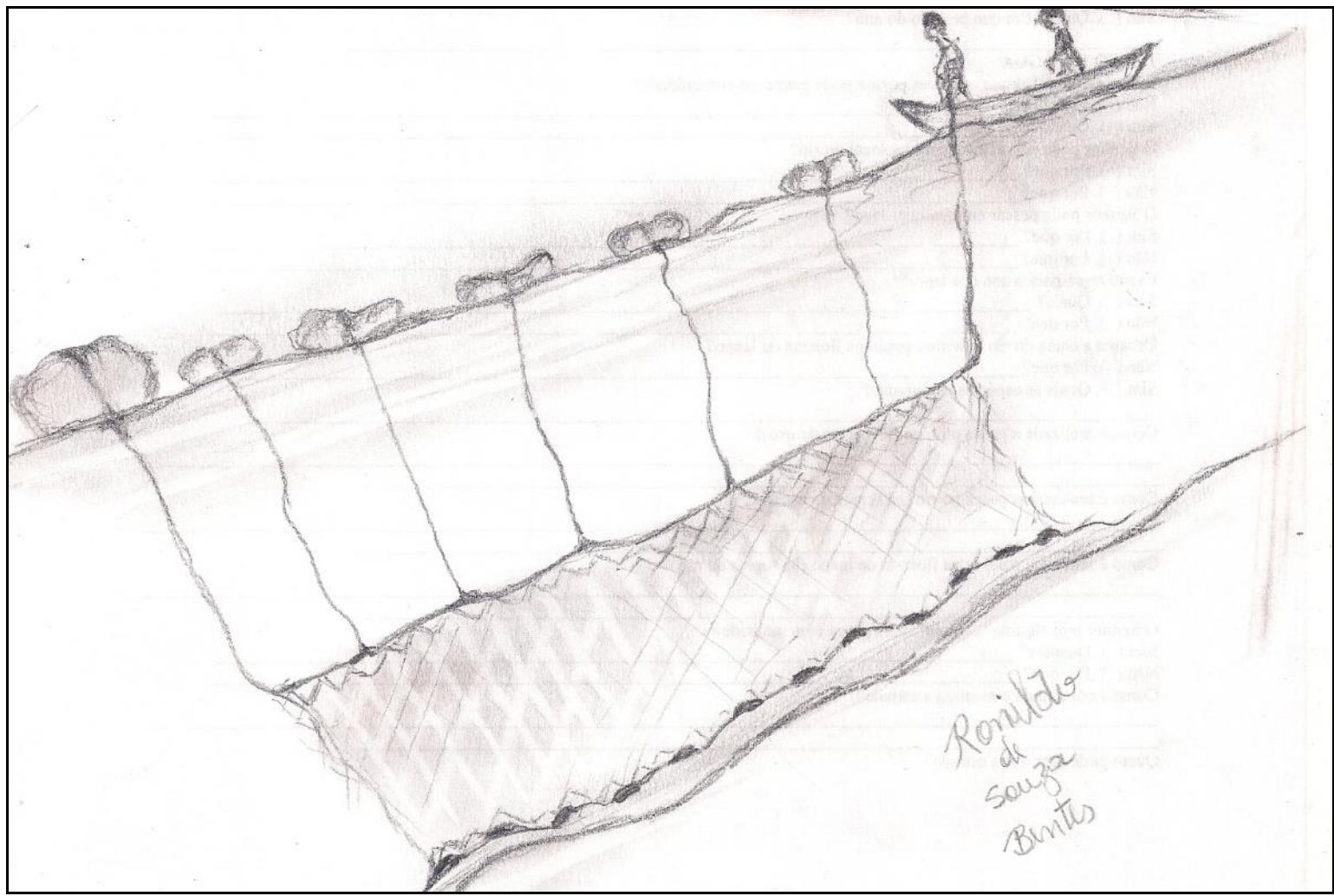

Figura 2: Pesca no Médio rio Amazonas - década de 2000. Desenho: Ronildo de Souza Bentes, 2015. Organizador: Nascimento, 2015. Trabalho de campo, 2014-2015.

O lanço comunica uma territorialidade, aqui interpretada de acordo com Claude Raffestin (1993[1980]) na obra Por uma geografia do poder, e Robert David Sack (1986) na obra Human Territoriality, its theory and history, conforme proposto por Cruz (2007). Antes é preciso considerar que o lanço de pesca só existe enquanto representação. Fora do plano subjetivo (na prática) o lanço é apenas uma porção do espaço, do rio, preparado para um fim específico, por isso, por si só é incapaz de comunicar a territorialidade.

Porque o espaço em si não é portador de regras, de territorialidades, as regras se dão mediante as relações de poder, ou seja, entre as pessoas, no território. "[...] A territorialidade se manifesta em todas as escalas espaciais e sociais; ela é consubstancial a todas as relações e seria possível dizer que, de certa forma, é a "face vivida" da "face agida" do poder" (RAFFESTIN, 1993, p. 161-162, grifos no original).

É importante que haja a demarcação do lanço pelos camponeses-ribeirinhos e, mais que isso, a criação de regras para que se distinga este dos demais espaços do rio. 
Entende-se que a territorialidade só existe mediante a representação dos sujeitos e por meio da elaboração de regras para o uso do espaço.

As regras de uso intencionam a manutenção, não mais do espaço em si, mas do espaço (produzido) apropriado pelo grupo, o território. Somente a territorialidade pode comunicar o controle do território da pesca, pois ela (a territorialidade) está inserida no campo das relações. A territorialidade só se manifesta nas relações entre os sujeitos (RAFFESTIN, 1993).

O lanço tem ao mesmo tempo existência objetiva, enquanto uma porção do rio, e subjetiva, enquanto uma representação, uma abstração do espaço (do rio) a partir duma utilidade imediata, uma porção do espaço preparado/apropriado para a pesca.

Assim, só os camponeses-ribeirinhos sabem quando o lanço deve ser utilizado, o período do ano em que determinadas espécies podem ser capturadas e quais os apetrechos apropriados, pois estas informações não são comunicadas doutra forma a não ser pela socialização por e para as turmas de pescadores.

Sendo o rio um espaço de acesso livre, como explicar a territorialidade neste caso? Talvez esta seja a melhor maneira de compreensão. Digamos que o rio seja um espaço como outro qualquer. Mas, os lanços são "construções" humanas no interior do rio.

Pelo fato do lanço conter trabalho humano (dos camponeses-ribeirinhos) na limpeza do leito do rio para a retirada dos troncos de árvores (paus), esta porção do rio passa a conter simbolicamente o direito ao acesso apenas àqueles que prepararam o lanço, ou a terceiros, mediante o consentimento destes e a devida observação de suas regras de uso. Isso também quer dizer que o lanço pode ser utilizado por pessoas de fora, de outras comunidades, por exemplo.

O consentimento, neste caso, é expresso pela observação/respeito do sistema de espera da vez, introduzido e fiscalizado pelos camponeses-ribeirinhos, o que não quer dizer ausência de conflitos. Quando um desavisado, ou mesmo quando alguém resolve intencionalmente descumprir o sistema de espera da vez este é imediatamente "punido" pelo grupo.

O grupo além de xingar os infratores, também lhes cortam a frente, ou seja, um dos camponeses-ribeirinhos lança sua rede à frente da rede do infrator impedindo-o de prosseguir no lance. Em casos extremos é cortada, com faca, a rede do infrator ou parte dela.

A construção do lanço de pesca não implica a alteração do espaço, não corresponde a territórios fechados ou cercados. Esses espaços não recebem nenhuma delimitação (fruto da construção humana), algo que possa servir para comunicar essa territorialidade.

Rapozo \& Witkoski (2010, p. 211) acrescentam que, embora não haja demarcações "[...] de uso específicas ou amparadas por leis, não significa que não há códigos de controle e conduta no uso dos recursos através de um grupo específico de comunidades...". 
É preciso entender neste caso como se estabelece o controle dos recursos pesqueiros por meio das territorialidades criadas pelas turmas de pescadores na pesca dos grandes bagres.

Robert Sack (1986) propôs uma interpretação de territorialidade bem próxima à de Gottman, mas aplicável em todas as escalas. Quando você tem crianças, diz ele, você pode impedi-las de abrir uma ou outra gaveta do seu escritório, de brincar com o computador, com o telefone ou o fax, de pegar livros das estantes e de colocá-los em qualquer lugar. A lista de proibições pode se estender ao infinito, o que diminui o efeito e prejudica sua eficácia. Impedindo pura e simplesmente o acesso das crianças ao escritório, com menos despesas você alcançará o resultado desejado. O território nasce então das estratégias de controle necessárias à vida social - uma outra maneira de dizer que ela exprime uma soberania. A abordagem de Robert Sack adquire importância por salientar que a ideia de territorialidade se aplica a todas as escalas, desde uma peça num apartamento até a de um Estado (CLAVAL, 1999, p. 8, grifo nosso).

Como os lanços de pesca no rio não correspondem a territórios fechados, o que assegura ao grupo o controle sobre o mesmo é o estabelecimento de suas regras de uso.

Considerando as ideias de Sack (1986), de que a territorialidade deve sempre envolver uma classificação por área e não por objetos, sem a necessidade de se enumerar as coisas que se pretendem proteger, pode-se dizer que, mais eficaz do que listar as espécies de pescados que são alvo da pesca camponesa, é impedir por completo o uso dos lanços de pesca por outros pescadores, por meio do estabelecimento das regras de uso, ou seja, o controle é realizado por área (por lanços) e não por objetos (por espécie de pescado). Isto aumenta a eficácia do controle sobre aquilo que se pretende proteger dentro de determinada área.

Como a construção do lanço de pesca não envolve a alteração do espaço, não havendo cercamentos, a territorialidade manifesta-se dependendo do nível das águas do rio. Terminado o período da pesca, os lanços de pesca são desativados pelos camponeses-ribeirinhos até a próxima enchente/cheia do rio (Figuras 3 e 4). 
TERRITORIALIDADES DA PESCA NO MÉDIO RIO AMAZONAS

\section{Die REVISTA GEONORTE}

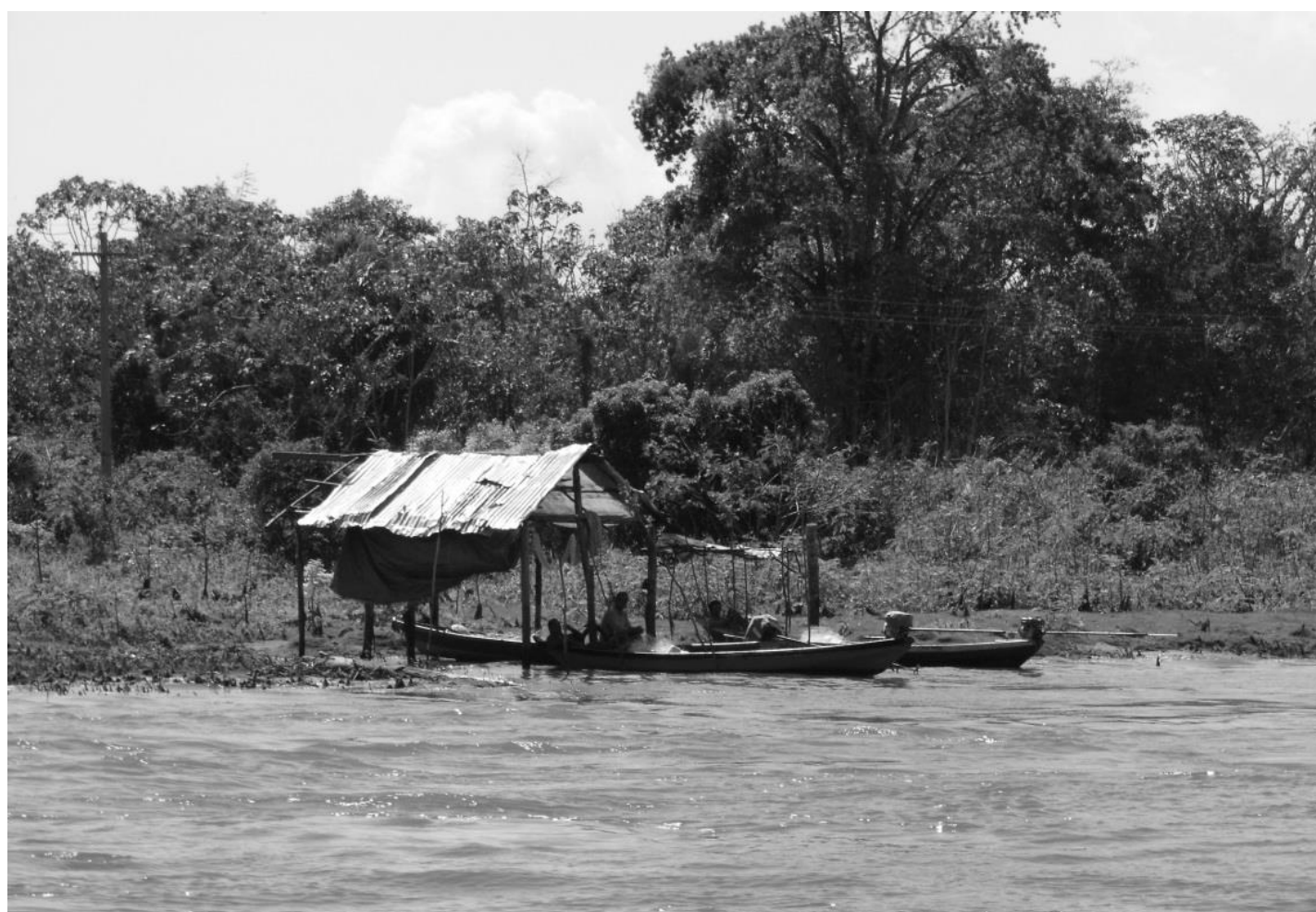

Figura 3: Ativação do lanço: pescadores no sistema de espera da vez. Fonte: Nascimento. Trabalho de campo, 02/08/2014.

Os lanços de pesca são instalados por volta do mês de março, quando o nível das águas do rio Amazonas está elevado, e são encerrados aproximadamente no mês de setembro, quando o nível das águas está baixo após o término da migração dos peixes na piracema.

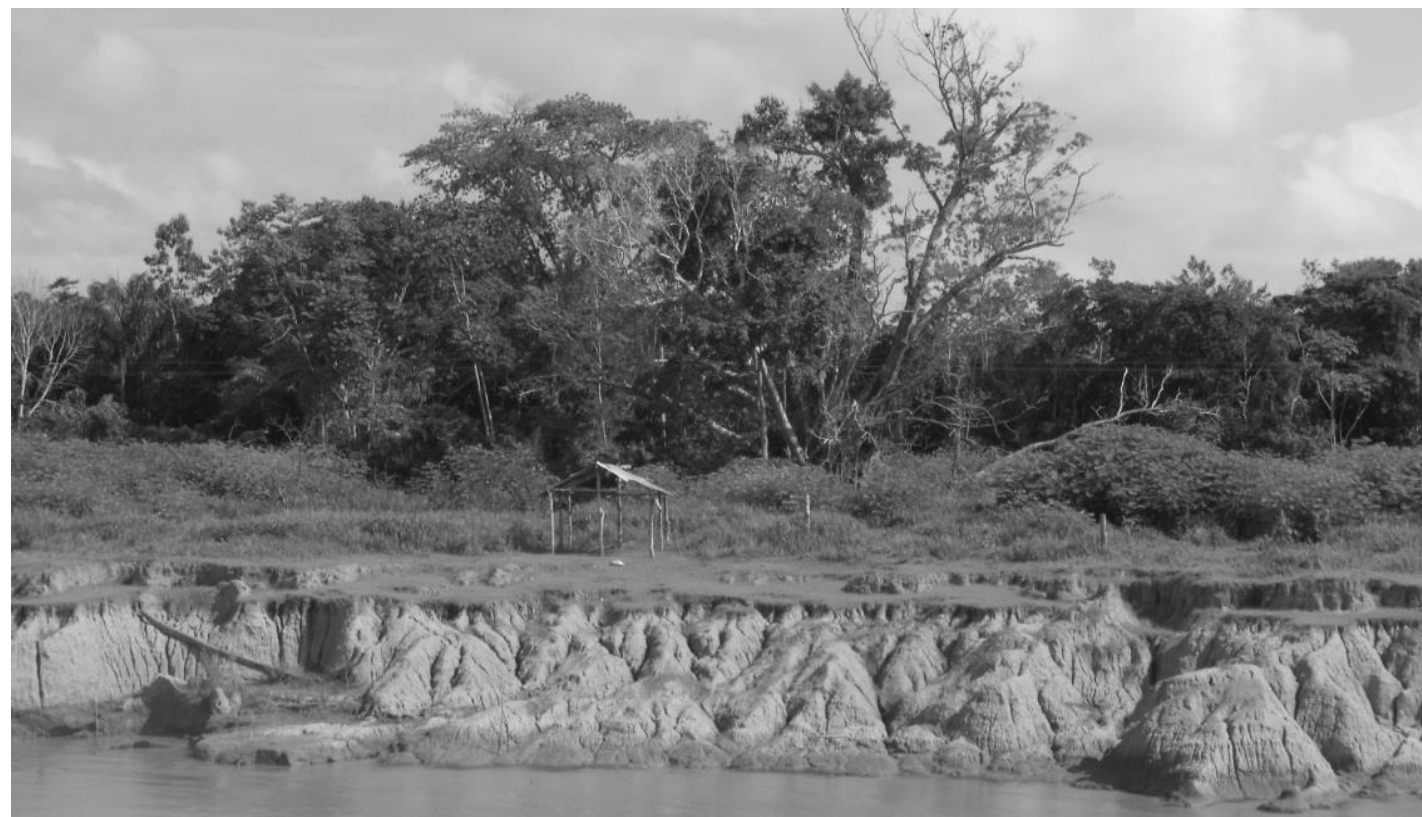

Figura 4: Desativação do lanço de pesca. Fonte: Nascimento. Trabalho de campo, 02.01.2015. 
Para os moradores da comunidade São Sebastião do Boto, depois dos peixes de couro/liso, o apapá (Pellona falvipinis, $P$. castelnaeana) é o principal peixe de escama capturado nos lanços de pesca, no ambiente de rio.

Tanto a classificação das classes de pescado, considerando o tamanho (comprimento ou peso mínimo) das espécies, quanto o preço/kg são determinados pela Casa Flutuante. A casa flutuante é uma moradia construída sobre toras de madeira que funcionam como boias. É onde se instala o comerciante atravessador que compra o pescado dos ribeirinhos.

A pesca do apapá estende-se entre os meses de março a setembro. Nesse período a pesca de peixes de escama, no ambiente de rio, objetiva principalmente a captura do apapá-amarelo em função do preço, que varia entre $R \$ 6,00$ (seis reais) e $R \$$ 5,00 (cinco reais) por quilo, preços pagos em 2014 e 2015. O pescado é comercializado com a casa flutuante que se estabelece na Costa do Amazonas. "Agora, em março, o "Bode" já está aí com o flutuante dele. Está seis reais o quilo do apapá-amarelo. Ano passado [2014] ficou cinco reais o quilo durante a safra toda" (R. O. S. 49 anos. Camponês-ribeirinho. Pesquisa de campo. Março de 2015).

Enquanto a captura dos bagres dura aproximadamente três meses entre julho e setembro, a captura do apapá tem permanecido por aproximadamente seis meses. Cabe destacar que a pesca no rio Amazonas visando à comercialização só cessa temporariamente entre os meses de novembro e janeiro, aproximadamente, quando o nível das águas no canal é menor, reduzindo a velocidade do rio e, com isso, prejudicando a descida/deslocamento das redes de pesca com a força das correntes. É nesse momento crítico que os lanços de pesca no rio Amazonas são "abandonados" até o ano seguinte.

Os lanços de pesca no rio Amazonas traduzem uma territorialidade ribeirinha construída com o intuito de assegurar o acesso aos recursos ictionaunísticos cuja demanda consumidora urbana regional tem contribuído para sua redução. As estratégias de controle sobre os locais de captura das espécies de pescado pelos grupos de pescadores contribuem para garantir o controle desses espaços frente à disputa ocasionada, sobretudo, pela escassez do pescado.

\section{CONSIDERAÇÕES FINAIS}

As espécies de fundo (os siluriformes) passaram a ser alvo da pesca camponesa motivando as territorialidades da pesca no ambiente de rio posterior à década de 1970, em substituição à pesca de espécies capturadas até então como a piraíba. O pescado capturado nos lanços de pesca tem sua comercialização assegurada no próprio local de captura das espécies, fato que motiva tal atividade entre os ribeirinhos.

As transformações na pesca foram acompanhadas pelas modificações do comércio regional de pescado que passou a atender a maior demanda consumidora urbana, 
como a criada pela Zona Franca de Manaus; pelo surgimento das redes de fios sintéticos e pela popularização do polietileno ou isopor como isolante térmico que permitiu a conservação do peixe refrigerado em substituição a salga do pescado.

Os lanços de pesca representam as territorialidades ribeirinhas construídas pelos grupos de pescadores para o uso comum do rio. Os lanços comunicam uma territorialidade expressa por meio do "sistema de espera da vez", instituída e fiscalizada pelos próprios pescadores. A observância das regras de uso é fundamental para redução dos conflitos, bem como para a manutenção dos territórios de pesca.

\section{AGRADECIMENTO}

Agradeço a FAPEAM - Fundação de Amparo à Pesquisa do Estado do Amazonas, pela concessão de Bolsa de Mestrado em Geografia.

\section{REFERÊNCIAS}

BATISTA, V.S.; ISAAC, V. J.; VIANA, J. P. Exploração e manejo dos recursos pesqueiros da Amazônia. P. 63-154. In: RUFFINO, M. L. Coord. A pesca e os recursos pesqueiros na Amazônia brasileira. Manaus: Ibama/ProVárzea, 2004. 272 p.

CANDIDO, A. Os parceiros do Rio Bonito: estudos sobre o caipira paulista. 11. ed. Rio de Janeiro: Ouro sobre Azul, 2010.

CLAVAL, P. O território na transição da pós-modernidade. Tradução e revisão de: Inah Vieira Lontra, Márcio de Oliveira e Rogério Haesbaert. GEOgraphia, ano 1, № 2, 1999. P. 7-26.

CRUZ, M.J. M. Territorialização camponesa na várzea da Amazônia. 274 p. (Tese de doutorado. Doutorado em Geografia Humana da Universidade de São Paulo). São Paulo: USP, 2007.

McGRATH, D. G.; GAMA, A. S. P.. A situação fundiária da várzea do rio Amazonas e experimentos de regularização fundiária nos estados do Pará e do Amazonas. P. 3557. In: BENATTI, J. H., et al. A questão fundiária e o manejo dos recursos naturais da várzea: análise para a elaboração de novos modelos jurídicos. Manaus: Edições Ibama/ProVárzea, 2005. 104 p.

PIRES, V. S. O sustento que vem das águas: dinâmica socioambiental da pesca artesanal na APA/Nhamundá em Parintins-AM. 153 p. (Dissertação. Mestrado em Ciências do Ambiente e Sustentabilidade na Amazônia. Universidade Federal do Amazonas). Manaus, 2015. 
RAFFESTIN, C. Por uma geografia do poder. Tradução de Maria Cecília França. São Paulo: Ática, 1993.

RAPOZO, P.; WITKOSKI, A. C.. Espaços de Uso Comum? A construção de territorialidades sociais como formas de controle do acesso aos recursos pesqueiros entre os pescadores no baixo rio Solimões, Manacapuru (AM). P. 199-222. In: VALENCIO, N.; PAULA, E. A.; WITKOSKI, A. C. Processos de territorialização e identidades sociais. RiMa Editora, 2010. 336 p.

SACK, R. D. Human Territoriality. Its theory and history. Cambridge University Press, 1986.

SANTOS, M. A natureza do espaço: técnica e tempo. Razão e emoção. 4. ed. São Paulo: Edusp, 2006.

SOUZA, M. L. Os conceitos fundamentais da pesquisa sócio-espacial. Rio de Janeiro: Bertrand Brasil, 2013. 